\title{
Lateral Maxillary Sinus Floor Elevation in presence of a sinus osteoma: A case report.
}

\author{
Mootaz MLOUKA ${ }^{1}$, Mohamed Tlili ${ }^{1}$, ali meddeb hamrouni ${ }^{1}$, raki selmi ${ }^{1}$, Faten Khanfir $^{1}$, \\ Mohamed Salah Khalfi ${ }^{1}$, and Faten Ben Amor ${ }^{1}$ \\ ${ }^{1}$ University of Monastir Faculty of Dental Medicine of Monastir
}

January 9, 2021

\begin{abstract}
Maxillary sinus grafting is a well-know procedure with high predictability used to to correct vertical bone defects in the posterior region of the maxilla.The presence of a sinus osteoma adds to its difficulty and may recquire a more specific case management depending on the lesion's extent.
\end{abstract}

Title : Lateral Maxillary Sinus Floor Elevation in presence of a sinus osteoma : A case report.

Authors : M.Mlouka, M. Tlili, A. Hamrouni, R. Selmi, F. Khanfir, M.S Khalfi, F. Ben Amor

Abstract :

Maxillary sinus grafting is a well-know procedure that has been used for a long time with high predictability in order to correct vertical bone defects in the posterior region of the maxilla. While the crestal approach is indicated in moderate vertical defects, the lateral approach is used when facing severe maxillary atrophy with a residual ridge hight inferior to $6 \mathrm{~mm}$.

Some benign tumors can develop inside of the paranasal cavities such as osteomas. They present as a slowgrowing, usually asymptomatic lesions, characterized by proliferation of compact or cancellous bone. they commonly occur in the frontal sinus, followed by the ethmoid and maxillary sinus. It's rarely encountered in the sphenoid sinus.

The presence of a sinus osteoma can be a challenge if a sinus floor elevation procedure must be performed. To our knowledge, this is the first case report of a maxillary sinus grafting in presence of a sinus osteoma.

Introduction :

Maxillary sinus grafting was first described by Dr. Hilt Tatum who modified the Caldwell-Luc technique in the 1970s, and it has been recognized as a procedure with high predictability to date (1).

Many factors can influence the difficulty and complexity of this intervention and must be thoroughly assessed before a lateral sinus augmentation, such as the presence of a bony septum, the location of the alveolar antral artery, the thickness of the schneiderian membrane, and more rarely the presence of a sinus osteoma.

Craniofacial osteomas may appear on any bone of the cranium or face or within a paranasal sinus. Osteomas within the paranasal sinus are relatively rare, they are found in $0.01 \%$ to $0.43 \%$ of patients; of these, up to $80 \%$ occur in the frontal sinus (2).

The maxillary sinus is involved in less than $2 \%$ of all cases, it usually appears on the lateral wall of the sinus (3). 
The current paper will present and discuss the management of a unitary posterior edentulim (tooth 16) with a severe vertical defect and the presence of an osteoma on the lateral wall of the sinus regarding the edentulous site.

Case presentation :

A 26-year old male patient was referred to the Outpatient and Implantology department of the university dental clinic of monastir. He was non-smoker and the medical history did not reveal any significant systemic diseases.

The chief-complaint was the replacement of the right upper first molar (tooth 16) which was extracted 5 years ago due to dental decay.

Clinically, no horizontal defect was objectified, the present prosthetic space and keratinized tissue were sufficient. An OPG and a CBCT were prescribed and showed a severe vertical defect with a residual ridge height of $2 \mathrm{~mm}$.

Moreover, on the inner side of the lateral wall of the maxillary sinus, an osteoma was fortouisly discovered. It had a corono apical long axis of $8 \mathrm{~mm}$ and a mesiodistal width of 5mm. (Fig 1, Fig 2)

This benign tumor was completely asymptomatic, but it was located in the site of the missing tooth and would certainly interfere with the lateral window design required in the intended bone augmentation procedure.

Sinus-graft with the lateral approach and delayed implant placement was decided. The patient was informed and consent was obtained.

After an initial mouth rinse with chlorhexidine digluconate $0.2 \%$, local anesthesia was carried using mepivacaïne $2 \%$ with epinephrine $1: 100,000$ (médicaïneß $2 \%$, Médis, Tunisia).

A crestal incision in the edentulous site, completed with an instrasulcular incision regarding tooth 17 and a releasing incision distal to tooth 15 enabled the relflexion of a full-thickness triangular flap with a sufficient visual access to the surgical site.

The excision of the lateral window, along with the part of the osteoma that impeded on it, was performed using piezoelectric instruments (Mectron@) in order to minimize the risk of perforation of the schneiderian membrane (Fig 3.a). The remaining part of the osteoma was kept in place.

The sinus membrane was elevated and a first resorbable membrane was placed beneath it to reinforce it and prevent a possile leak of the bone particles into the antrum (Fig 3.b ; 3.c).

A xenograft (Apatos - OsteoBiol ( $)$ ) was condensed to fill the antral cavity (Fig 3.d). The site was then covered with a second resorbable membrane and the flap was repositioned and sutured. (Fig 3.e)

A post-operative retroalveolar radiography was immediately taken (Fig 3.f). An association of amoxicillin/clavulanic acid (1g every 8 hours for 10 days) was prescribed post-operatively. Sutures were removed after 10 days, and implant placement was programmed in 6 months (Fig 3.g)

Discussion :

Lateral Sinus floor elevation is one of the most widely used augmentation procedures. It enables implant placement in the posterior region of an atrophic maxilla, where the bone is generally reduced as a result of two phenomenons : alveolar ridge resorption due to increased osteoclastic activity following tooth loss and sinus extention due its pneumatization (11).

While sinus floor elevation by the transalveolar approach is indicated in moderate vertical defects $(>=7 \mathrm{~mm})$, the lateral approach is used when facing severe maxillary atrophy (ridge hight $<6 \mathrm{~mm}$ ). A minimal residual height of $4 \mathrm{~mm}$ indicates immediate implant placement, otherwise, the bone quantity would be insufficient to obtain primary stability, and implant surgery must be delayed (table 1) (5). 


\begin{tabular}{ll}
\hline Residual ridge height & Case management \\
\hline [?]10 $\mathrm{mm}$ (Class A) & Implant placement \\
7 to $9 \mathrm{~mm}$ (Class B) & Crestal Sinus Floor elevation with immediate implant \\
4 to $6 \mathrm{~mm}$ (Class C) & Lateral Sinus Floor elevation with immediate or delayed implant \\
1 to $3 \mathrm{~mm}$ (Class D) & Lateral Sinus Floor elevation with delayed implant \\
\hline
\end{tabular}

Table 1: Jensen's classification following the Sinus Consensus Conference (1996) (5)

In order to assess the complexity of the lateral sinus floor elevation technique, Tiziano et al. suggested a difficulty score based on anatomical and patient-related factors (6). Many of these factors were found in our case such as the presence of a medio lateral septum and the presence of adjacent teeth since there was only one tooth missing.

The presence of an osteoma isn't found in the litterature to be a difficulty-increasing factor. This is probably due to their low frequency in general, and more specifically in sinuses requiring a floor elevation procedure.

In our case, the management of the osteoma consisted in a partial excision of the segment impeding on the lateral window. The remaining part will be monitored with periodic radiographs in order to assess its growth rate. The total excision was not indicated since the benign tumor was completely asymptomatic.

According to the meta-analysis of Jordi et al., the use of rotating burs resulted in a significantly higher risk of membrane perforations during the osteotomy compared to the piezoelectric instruments. The average incidence of perforation during Lateral maxillary sinus augmentation drops from $24 \%$ for rotating instruments to $8 \%$ for piezosurgery (10).

Medium-sized osteomas might have required a total excision in the same time as the sinus floor elevation in order to avoid futher growth. A two-stage option can be planned in case of large tumors, starting with the removal of the osteoma followed by the sinus augmentation after a healing period. In this case, an endoscopic approach would be recommended (8), since the caldwell-luc technique usually makes the sinus floor elevation highly complex because scar tissue is much more difficult to manipulate than the physiological one (12).

Conclusion :

Even though lateral sinus floor elevation is a well-documented procedure, its complexity is greatly influenced by anatomical and patient-related factors. A thorough clinical examination completed with a radiographic assessment with $\mathrm{CBCT}$ or $\mathrm{CT}$ reconstructions is mandatory before the intervention. To our knowledge, this is the first published case of a sinus graft in presence of a lateral wall osteoma. The management of such obstacles is decided on a case-by-case basis after evaluation of the benefit/risk ratio.

\section{Conflict of Interests}

The authors declare that there is no conflict of interests regarding the publication of this paper.

Authors' details:

Author 1 : Mootaz Mlouka ${ }^{1}$ : ensured patient follow-up and manuscript redaction.

Author 2 : Mohamed Tlili ${ }^{2}$ : surgery performance and manuscript revision.

Author 3 : Ali Hamrouni ${ }^{1}$ : manuscript drafting.

Author 4 : Raki Selmi ${ }^{1}$ : manuscript drafting.

Author 5 : Faten Khanfir ${ }^{2}$ : manuscript revision.

Author 6 : Mohamed Salah Khalfi ${ }^{3}$ : manuscript revison.

Author 7 : Faten Ben Amor $^{3}$ : manuscript revision. 
${ }^{1}$ Resident in Anatomy and Oral Surgery

${ }^{2}$ Assistant professor in Anatomy and Oral Surgery

3 Professor in Anatomy

University/Resarch Unit:

University of Monastir, Faculty of Dental Medicine, Research Laboratory of Oral Health and Oro Facial Rehabilitation, LR12ES11, 5000, Monastir, Tunisia;

References :

1. Tatum H Jr. 1986. Maxillary and sinus implant reconstructions. Dent Clin North Am ;30:207-229

2. Firat D, Sirin Y, Bilgic B, Ozyuvaci H. 2005. Large central osteoma of the maxillary antrum. Dentomaxillofac Radiol ;34:322-325

3. Zouloumis l, lazaridis n, maria p, et al. 2005. Osteoma of the ethmoidal sinus: a rare case of recurrence. Br J oral maxillofac Surg;43:520-522.

4. Kopecká D., Šimůnek A., Brázda T., Somanathan R.V.2006. Potřeba laterálního sinus liftu při ošetřování dorzálního úseku horní čelisti dentálními implantáty. Čes. Stomat., 106, 2: 56-58

5. Jensen OT, Shulman LB, Block MS, Iacono VJ. 1998. Report of the sinus consensus conference of 1996. Int. J. Oral Maxillofac. Implants; 13(Suppl):11-3

6. Testori T, Tavelli L, Yu S-H, Scaini R, Darnahal A, Wallace S, et al. 2020. Maxillary Sinus Elevation Difficulty Score with Lateral Wall Technique. The International Journal of Oral \& Maxillofacial Implants.;35(3):631-638

7. Beretta M, Cicciù M, Bramanti E, Maiorana C. 2012. Schneider Membrane Elevation in Presence of Sinus Septa: Anatomic Features and Surgical Management. International Journal of Dentistry; 2012:1-6.

8. Romano A, Dell'Aversana Orabona G, Pansini A, Abbate V, Cama A, Iaconetta G, et al. 2019. Endoscopic approach for paranasal sinuses osteomas: Our experience and review of literature. Oral and Maxillofacial Surgery Cases;5(2):100094.

9. Wallace SS, Mazor Z, Froum SJ, Cho SC, Tarnow DP. 2007. Schneiderian membrane perforation rate during sinus elevation using piezosurgery : clinical results of 100 consecutive cases. Int J Periodontics Restorative Dent; 27(5) : 413-419

10. Jordi C, Mukaddam K, Lambrecht JT, Kuhl S. 2018. Membrane perforation rate in lateral maxillary sinus floor augmentation using conventional rotating instruments and piezoelectric device - a meta-analysis. Int J Implant Dent. ;4(1):3.

11. Tarun Kumar A, Anand U. Maxillary sinus augmentation. J Int Clin Dent Res Organ. 2015;7(3):81.

12. Šimůnek A, Kopecká D, Brázda T, Somanathan RV. 2007. Is lateral sinus lift an effective and safe technique? Contemplations after the performance of one thousand surgeries. Implantologie Journal,:5. 

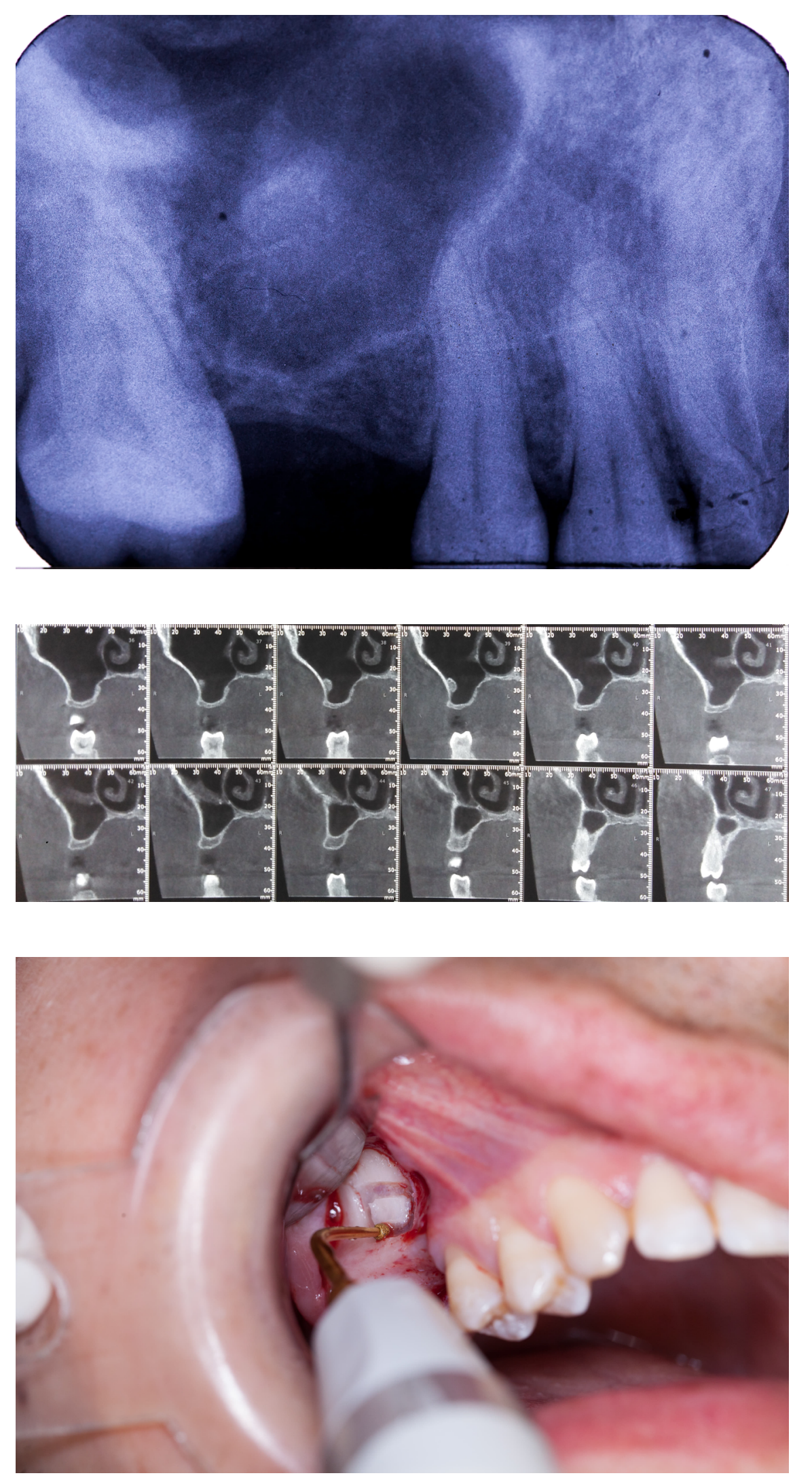

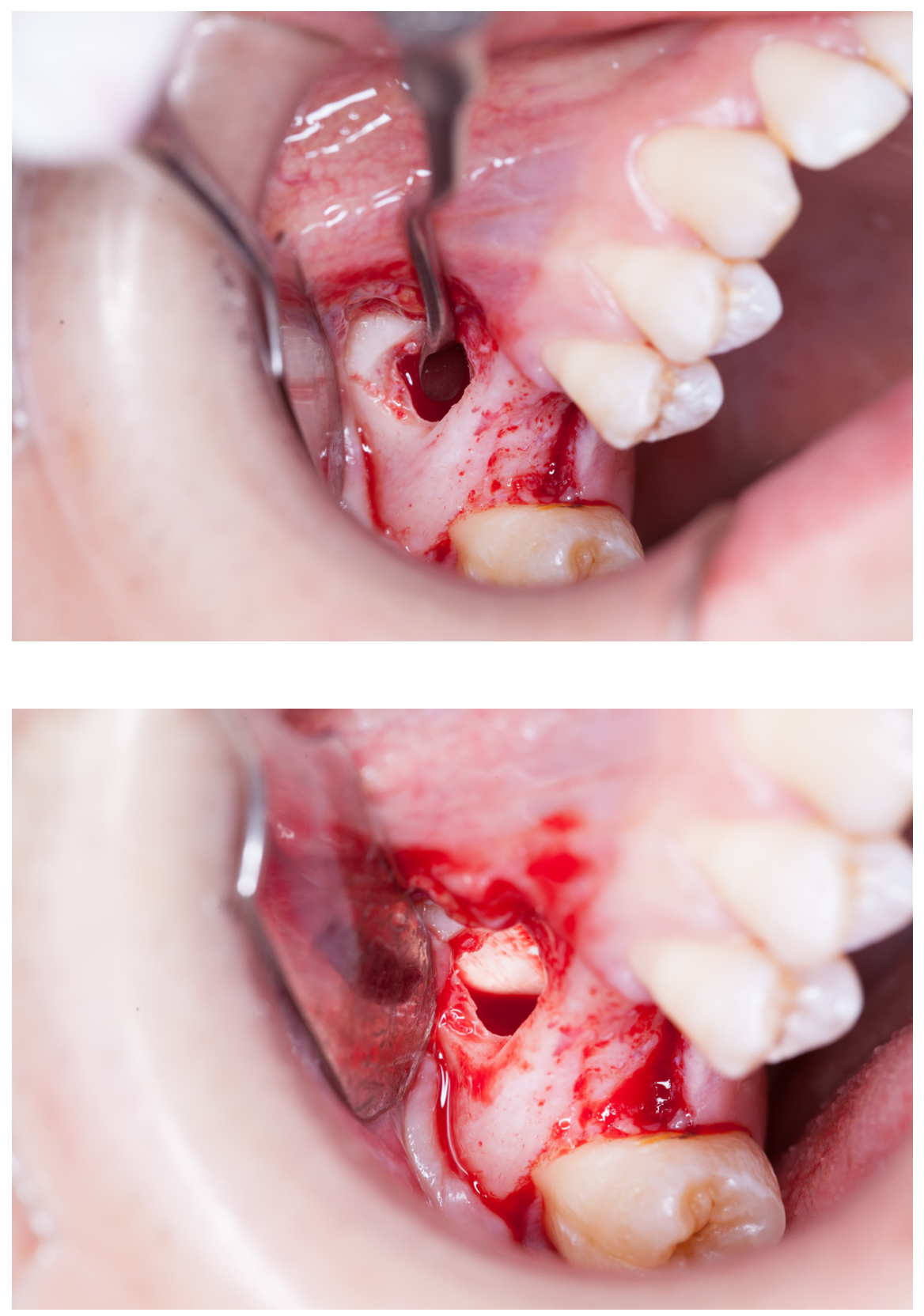

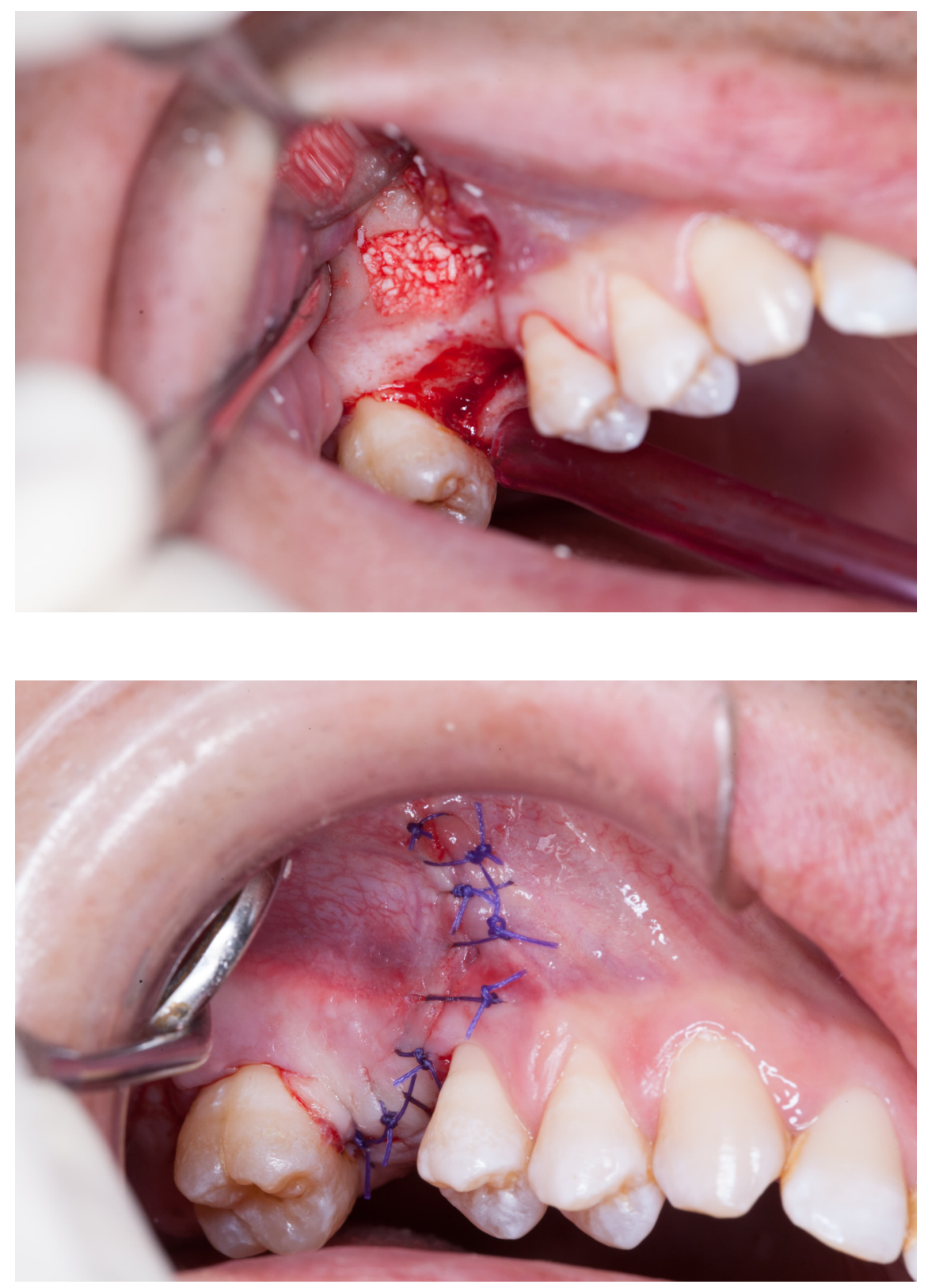

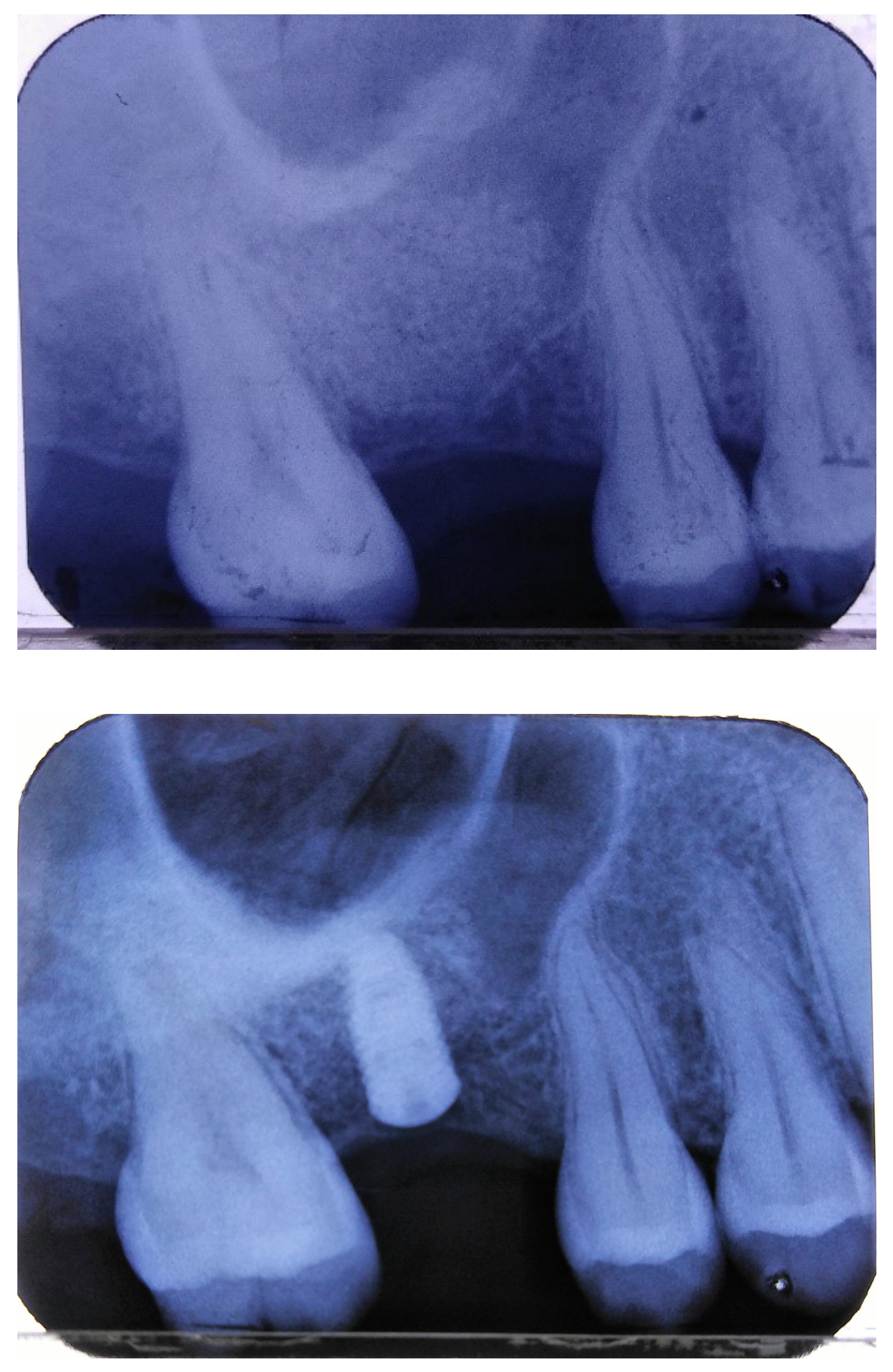